Fourth International Conference on Sustainable Construction Materials and Technologies http://www.claisse.info/Proceedings.htm

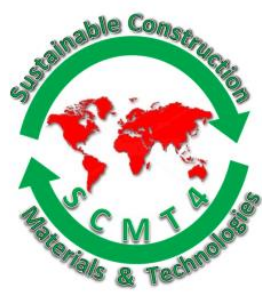

SCMT4

Las Vegas, USA, August 7-11, 2016

\title{
Freezing Damage Mechanism in Model Microchannels and Vacuum Curing on Cement Paste to Improve Frost Damage Resistance
}

\author{
Yuya Sakai ${ }^{1 \mathrm{a}}$, Tomohisa Kamada ${ }^{1 b}$, and Toshiharu Kishi ${ }^{1 \mathrm{c}}$ \\ ${ }^{1}$ Institute of Industrial Science; the University of Tokyo - 4-6-1, Komaba, Meguro, Tokyo, Japan. \\ ${ }^{1 a}$ Email: <ysakai@iis.u-tokyo.ac.jp>, ${ }^{1 b}$ Email: 〈tkamada@iis.u-tokyo.ac.jp>, \\ ${ }^{1 c}$ Email: <kishi@iis.u-tokyo.ac.jp>.
}

\begin{abstract}
To understand the conditions surrounding frost damage of concrete, freezing and thawing tests were executed on microchips containing microchannels of various geometries. The straight channels remained intact, and the channels having ink bottle geometries suffered frost damage. The channels with ink bottle profiles avoided frost damage when air remained in their cavities. After water permeation, air remained in channels having a large ratio of cavity to neck volume. Often, air is entrained to fresh concrete as a means of improving frost damage resistance. The results of this study indicate the importance of air entrapment during water permeation. Based on the results of the microchannel study, cement paste specimens were cured under reduced pressure to investigate the hypothesized improvement in resistance to frost damage. Freezing and thawing of hardened cement paste specimens containing AE water reducing agent resulted in surface deterioration. On the other hand, vacuumed cement paste specimens suffered almost no damage. These results indicate, under our experimental condition, vacuum curing as an effective means of reducing frost damage and also support the observations and results of the microchannel study.
\end{abstract}

\section{INTRODUCTION}

It is difficult to both evaluate and ensure resistance against frost damage of concrete. Air spacing has previously been used as a factor in assessing frost damage resistance [Marchard et al. 1994; Pigeon and Pleau 1995]. However, a low correlation between air spacing and frost damage resistance has been pointed out recently [Sakata et al. 2012]. Admixtures add another element of complexity; for example, silica fume admixtures cause changes to air spacing that improve resistance to frost damage [Pigeon et al., 1986], and fly ash admixtures reduce resistance to scaling [Gebler and Klieger 1986; Bilodeau and Malhotra 1992]. The condition of curing is also a factor affecting frost damage resistance; some research shows curing has little effect on frost damage resistance [Klieger and Gebler 1987; Afrani and Rogers 1994], but other research concludes that curing outdoors could accelerate damage, particularly on concrete with low W/C [Hama et al. 2003]. Furthermore, Tabata et al. [1986] show that mild drying reduces frost damage, while heavy drying accelerates the deterioration. These examples demonstrate the complex nature regarding frost damage of concrete, and the challenge involved in evaluating or ensuring resistance against it. Understanding the conditions for the damage is helpful to the eradication of frost damage from concrete structures and the evaluation of resistance to the damage. The objectives of this paper include understanding the factors affecting frost damage on concrete and developing a cement paste 
with high frost damage resistance. To identify relevant factors, water permeation and frost damage were studied using microchannels fabricated on glass slides. The study revealed that the larger ratios of cavity to neck volume of the ink bottle channel type were effective in reducing frost damage. In accordance with this finding, vacuum environments were used to cure cement paste specimens producing enlarged cavities, and the frost damage resistance was subsequently examined.

\section{EXPERIMENT DESIGN}

\section{Microchannel geometry}

Fabrication. Microchips (Photo 1) were fabricated with glass slides (soda lime glass, $76 \times 26 \times 1.3 \mathrm{~mm}$ ). One microchip was composed of two slides; microchannels were milled on one slide and holes of $1 \mathrm{~mm}$ in diameter were made on another slide. The machining was done with an NC processing machine. The two machined glass slides were cleaned with pure water and a melamine sponge, and immersed into solution of one part hydrogen peroxide to three parts sulfuric acid. The slides were rinsed with pure water, dried with duster spray, and pressed against each other to adhere by hydrogen bond. The bonded glass slides were baked at $645{ }^{\circ} \mathrm{C}$ for 5 hours and cooled slowly. The slides were bonded to each other with enough strength to undergo punching failure rather than detachment from each other when water in the channels was frozen. Each microchip contained five microchannels with different geometries to study the effect of channel shape and size on frost damage. Basic designs of the five microchannels are shown in figure 1. One channel had a straight profile and the remaining four had ink bottle profiles with different cavity areas and neck lengths. All channels had a depth of $500 \mu \mathrm{m}$ and the straight channel and necks of ink bottle channels had a width of $1000 \mu \mathrm{m}$. The dimensions of the cavities are shown in figure 1 . After machining the glass slides, the dimensions of the channels were confirmed using a surface roughness tester. Additionally, in some experiments, microchips containing microchannels with widths and depths of $500 \mu \mathrm{m}$ and $250 \mu \mathrm{m}$ were used. Lastly, in some experiments, microchips had similar geometries to those found in figure 1 but contained only inlets, and no outlets.

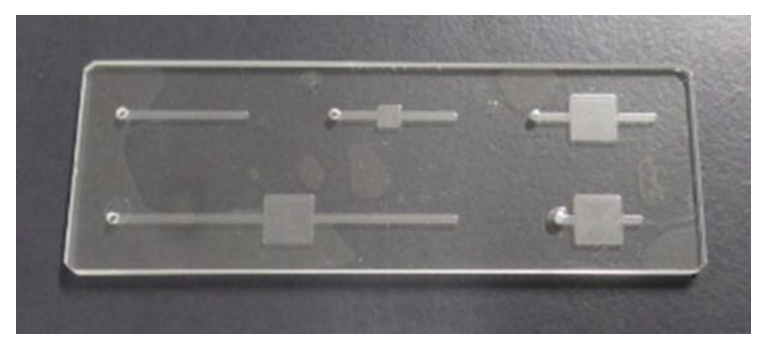

\section{Photo 1. Fabricated microchip}

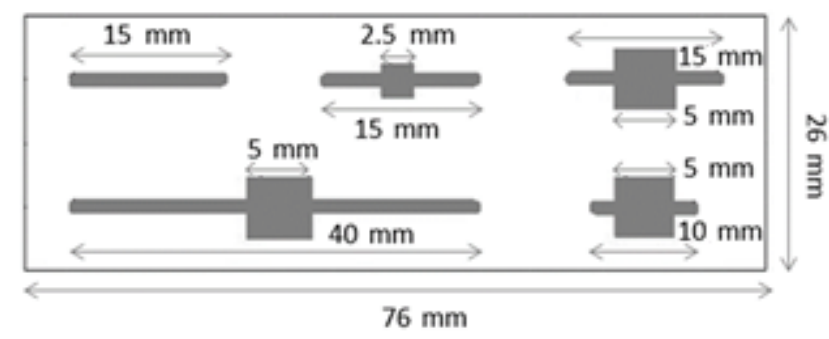

Figure. 1. Design of microchannels

Water permeation. Microchips were immersed in water of $20{ }^{\circ} \mathrm{C}$ in a graduated cylinder, and water permeation into the channels was observed.

Frost damage. Water was introduced to the microchannels and frozen to study the relationship between the channel geometry and frost damage. Water was frozen with a low-temperature liquid tank. A floating steel tray containing the water-saturated microchips was placed upon antifreezing solution in the tank. The water in the microchips was frozen in two ways: gradually decreasing the temperature from $20{ }^{\circ} \mathrm{C}$ to $-20^{\circ} \mathrm{C}$ over the course of 12 hours, and having the initial temperature of the tank be $-20^{\circ} \mathrm{C}$. In both cases, the microchips were observed one hour after the temperature reached $-20^{\circ} \mathrm{C}$. If damage was not observed via cracking of the glass, the microchip was put in a room at $20^{\circ} \mathrm{C}$ for three hours to melt the ice and the water was frozen again, up to 10 cycles. 
Air bubbles in channels. Air remained in some channels after water permeation. To study the effect of remaining air on frost damage, two types of chips, with and without air, were prepared and frozen (Photo 2). Air was introduced to the channel using a micropipette. Because the air volume was difficult to control, the ratio of air to cavity areas (observed from the top) ranged from $10 \%$ to $22 \%$. The water in the channels was frozen using the same technique previously described.

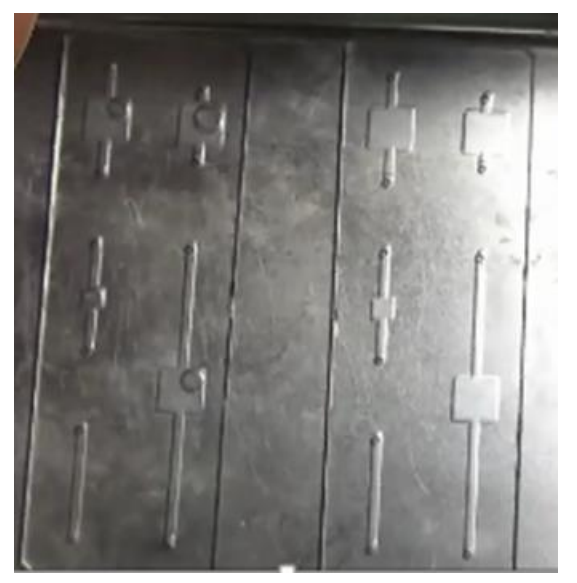

\section{Photo 2. Channels with and without air (left: with air, right: without air)}

\section{Cement paste}

Specimen preparation. Cement paste of $\mathrm{W} / \mathrm{C}=40 \%$ with or without air entraining (AE) water reducing agent $(0.5 \% /$ cement weight $)$ was prepared with ordinary Portland cement $\left(\right.$ density $\left.=3.15 \mathrm{~g} / \mathrm{cm}^{3}\right)$. The cement paste was placed in plastic cylindrical molds $(\varphi 50 \times 100 \mathrm{~mm})$ and cured under atmospheric pressure $\left(20{ }^{\circ} \mathrm{C}, 0.10 \mathrm{MPa}\right)$ or vacuum $\left(20{ }^{\circ} \mathrm{C}, 0.02 \mathrm{MPa}\right)$ for 24 hours. Vacuum curing was achieved using a desiccator of reduced pressure acquired via vacuum pump. The specimens were named A0, A0.5, $\mathrm{V} 0$ and V0.5. A and V stand for atmospheric pressure and vacuum, respectively, and the numbers indicate the amount of AE water reducing agent. As seen in Photo 3, V0 specimens, located at the front, expanded and overflowed the molds. Vacuum curing was expected to reduce frost damage on the cement paste since the study of microchannel geometry indicated that channels with a larger ratio of cavity to neck volume reduced frost damage. Vacuum curing was expected to achieve this effect because air bubbles increase in size under vacuuming, by a factor proportional to the initial air bubble size raised to the power of $3 / 2$ [Kijito et al. 2009]. The specimens were demolded and immersed in water $\left(20^{\circ} \mathrm{C}\right.$, atmospheric pressure) 24 hours after casting. After 7 days of aging, the specimens were moved to a desiccator $\left(20^{\circ} \mathrm{C}, \mathrm{RH} 60 \%\right)$. After four days, the specimens were immersed in water for three days. Freezing and thawing test was executed on the 14th day after casting.

Compressive strength and bulk density. Compressive strength of the specimens was measured at 14day age with a loading rate of $30 \mathrm{kN} / \mathrm{min}(0.25 \mathrm{~N} / \mathrm{mm} 2 \cdot \mathrm{s})$. Before the test, the height, diameter, and mass of the specimens were measured, and the bulk density was calculated. Compressive strength and bulk density were obtained from three specimens of each case to calculate the average value.

Porosity. The porosity of the specimens was measured with mercury intrusion porosimetry (MIP). On the 14th day after casting, the MIP sample was collected from the center of the specimens and crushed into 3 $\times 3 \times 3 \mathrm{~mm}$ cubes. The cubes were immersed in acetone for 24 hours and dried under an absolute pressure of $10 \mathrm{~Pa}$ for 24 hours. The samples used for MIP had masses of $1.0 \mathrm{~g}$.

Freezing and thawing test. As with the microchips, freezing and thawing cycles of the specimens were 
accomplished using a low-temperature liquid tank. Specimens were placed horizontally on a floating tray in antifreeze solution. Water was poured into the tray until the distance between the tops of the specimens and the water surface reached $3 \mathrm{~mm}$. To prevent the tray from overturning, glass slides were placed on the tray to prevent the specimens from rolling. A 12 hour cycle in which the temperature went from $20^{\circ} \mathrm{C}$ to $20{ }^{\circ} \mathrm{C}$ and back to $20{ }^{\circ} \mathrm{C}$ (figure 2) was performed 100 times. The frost damage on the samples was evaluated by mass reduction.

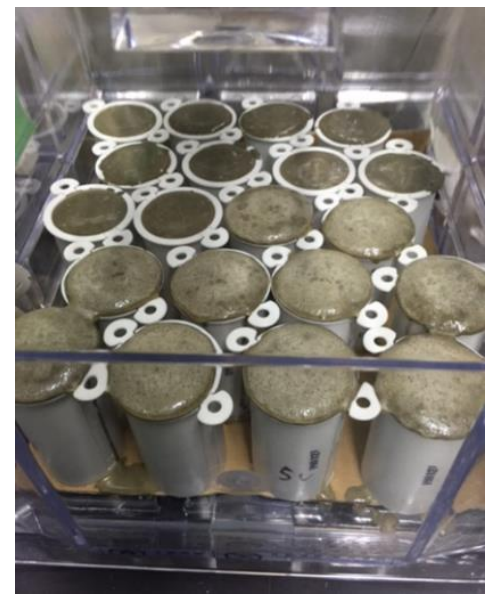

Photo. 3. Cement paste under vacuum

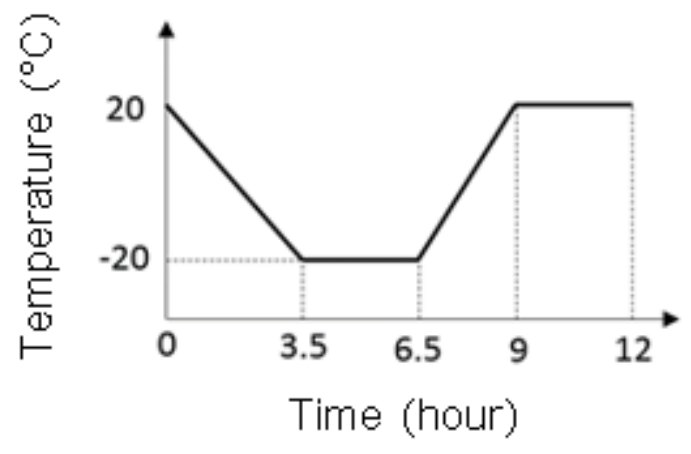

Figure 2. Temperature pattern in freezing and thawing test

\section{RESULTS}

\section{Microchannel geometry}

Water permeation into microchannels. The channels with both an inlet and an outlet filled with water immediately after the inlet were submersed in water. Conversely, it took several minutes to several hours (varied depending on the channel type) for the microchannels without an outlet to form a meniscus at their dead end. The channels filled from their dead ends (bottom of Photo 4), as opposed to their inlets. Meniscus formation tended to take more time in longer channel geometries. The air in the channels was pushed out (Photo 5) as the water filled them. The air was removed completely from some channels but remained in the cavities of channels having larger ratios of cavity to neck volume. For these channel geometries, remaining air occupied a large portion of the cavity (Photo 4). The size of the air bubble in the cavity was consistent over the course of one week. No visible air remained in the straight channels.

Effect of channel geometry on frost damage in microchips. The microchannels were filled with tap water and frozen. Photo 6 shows microchannels of $500 \mu \mathrm{m}$ in depth after freezing. In the photo, each channel is separated but their dimensions are the same as those in figure 1. Regardless of the freezing pattern, the straight channel was not damaged and the other ink bottle channels were cracked or punched. The channels with smaller cavities suffered small cracks in the first freezing; however, punching occurred at the subsequent freezings. Photo 6 shows the results in which the temperature was decreased gradually for 12 hours. Here, the microchannels of $250 \mu \mathrm{m}$ in depth suffered only small cracks (Photo 7) after first freezing. However, during the third freezing punching fracture was observed. The straight channels suffered no damage even after ten cycles of freezing and thawing. 


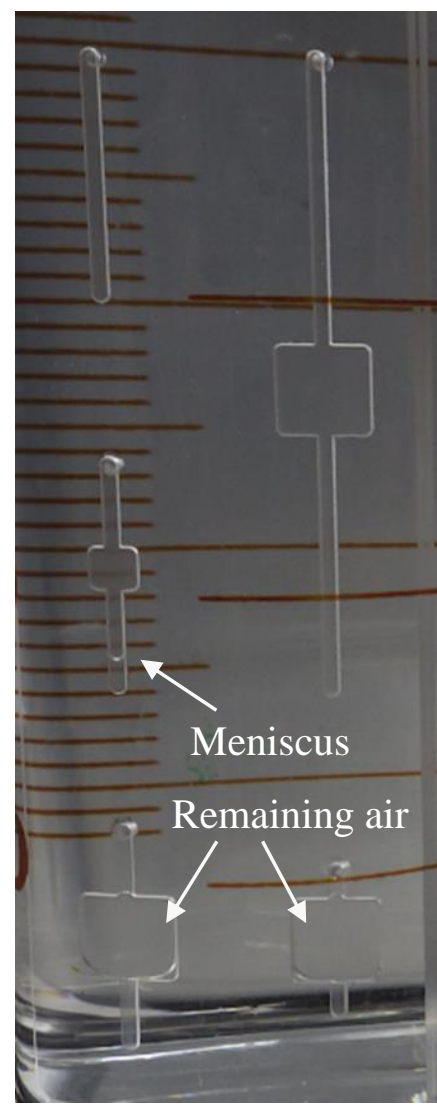

(a) 4 hours

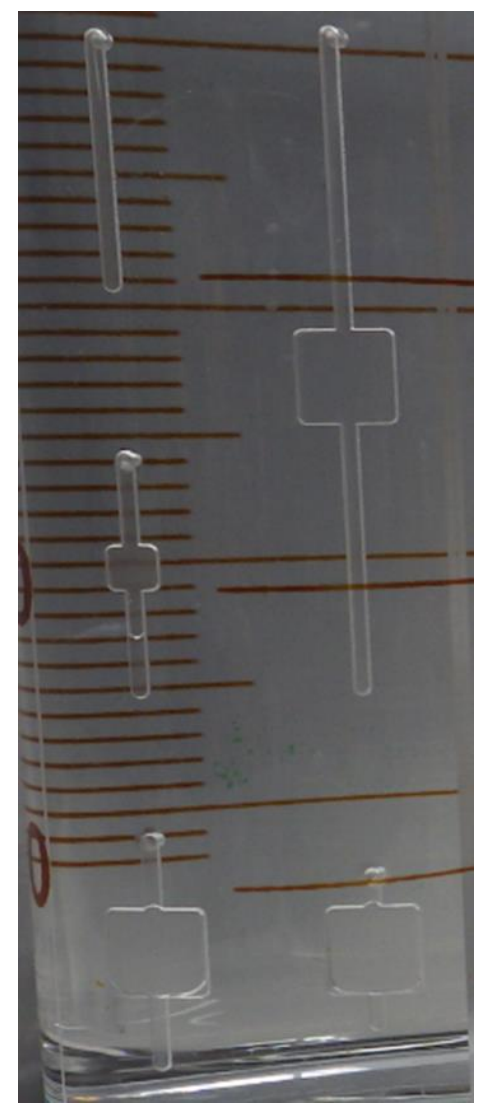

(b) 8 hours

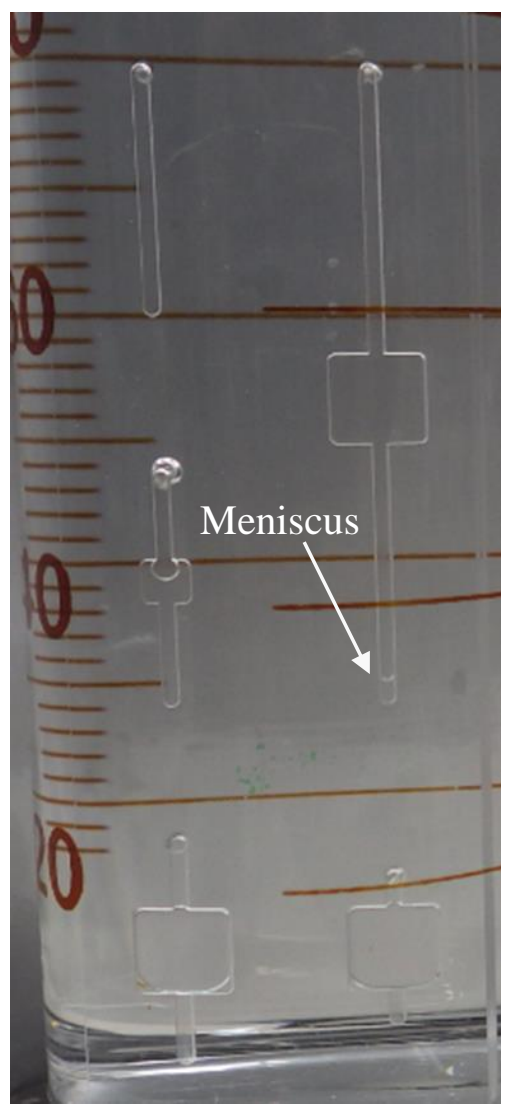

(c) 24 hours

Photo 4. Water permeation into microchannels after varying elapsed times of immersion

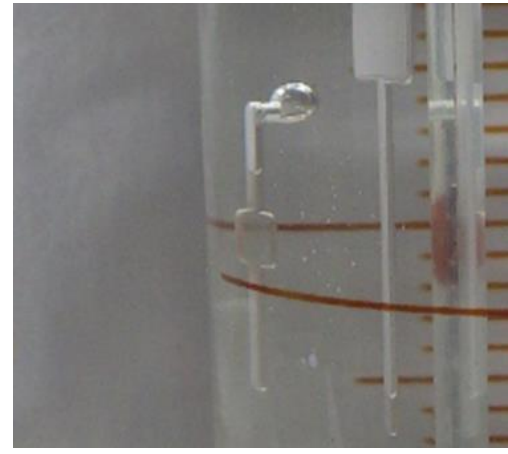

Photo 5. Air pushed out of channel

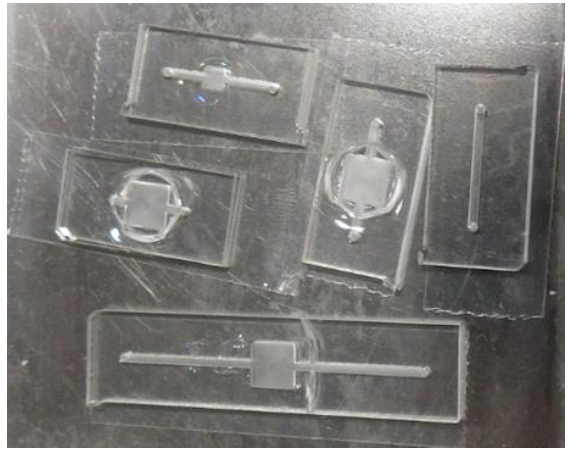

Photo 6. Damaged channels after freezing

Effect of remaining air on frost damage of microchips. The microchips with and without remaining air bubbles were frozen. Water-saturated channels suffered punching upon freezing but channels with air did not, even after ten cycles of freezing and thawing (Photo 8). Photo 9 shows the magnified air bubble before and after the water was frozen. 


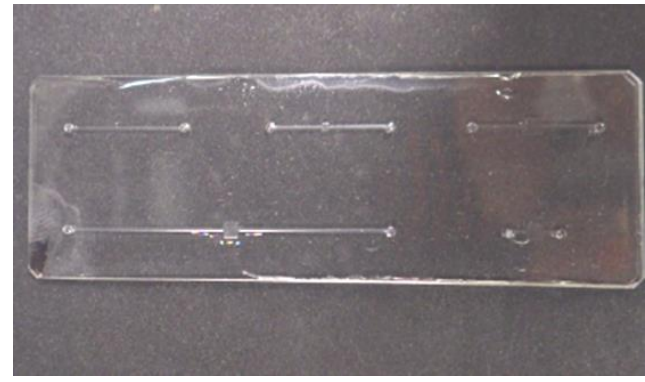

Photo 7. Damage in smaller channels

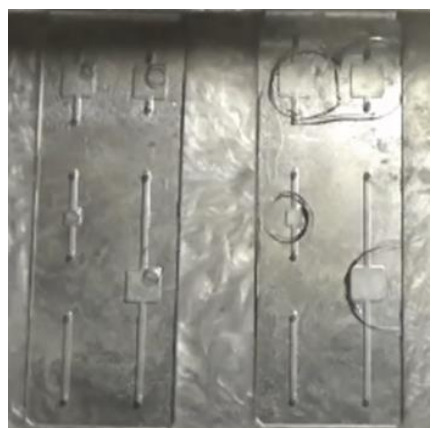
Photo 8. Effect of air on frost damage

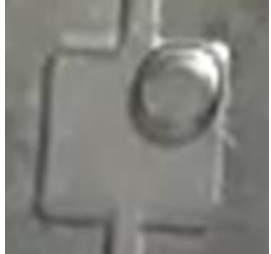

(a) Before

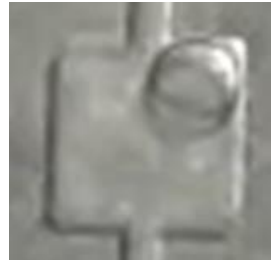

(b) After

\section{Photo 9. Air bubble before and after freezing}

\section{Cement paste}

Compressive strength and bulk density. Compressive strength and bulk density are shown in figure 3 . Vacuum curing reduced both compressive strength and bulk density in V0 and V0.5 specimens when compared with their A0 and A0.5 counterparts. AE water reducing agent reduced bulk density and increased compressive strength for specimens cured under atmospheric pressure (A0 and A0.5).

Porosity. Porosity measured with MIP is shown in figure 4. Specimens that were vacuum cured or had $\mathrm{AE}$ water reducing agent (V0, V0.5, A0.5) showed increased porosity compared with $\mathrm{A} 0$ for pores with diameters of 100-200 nm. Vacuum cured specimen V0 showed reduced porosity for pores with diameters of 30-40 nm compared to A0. Specimens V0 and A0.5 demonstrated similar porosity curves for pores larger than $20 \mathrm{~nm}$ in diameter. A0.5 and $\mathrm{V} 0$ had lower total porosity than A0.

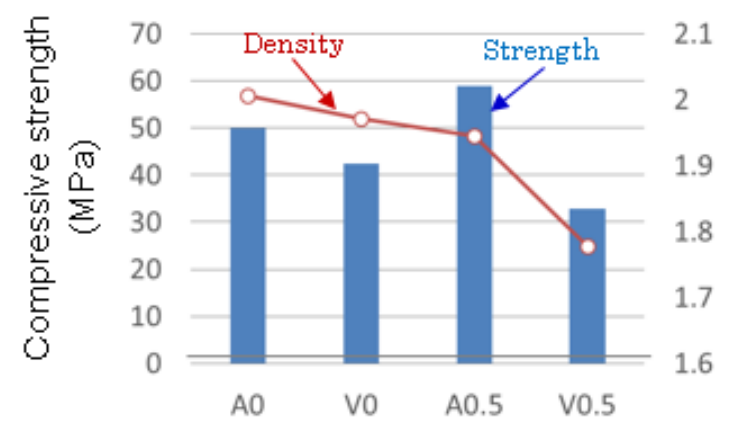

Figure 3. Compressive strength and bulk density

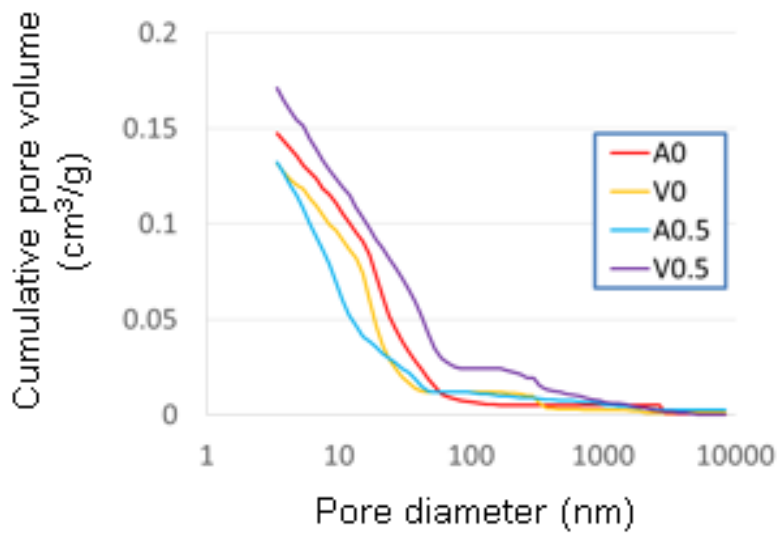

Figure 4. Pore size distribution

Freezing and thawing test. Figure 5 shows the mass change induced by frost damage. Over 100 cycles of freezing and thawing, A0 collapsed completely and V0 suffered the least amount of damage (Photo 10). The specimens with $\mathrm{AE}$ water reducing agent (A0.5, V0.5) did not collapse, but showed surface deterioration. A few large fragments fell off of specimen A0.5. 


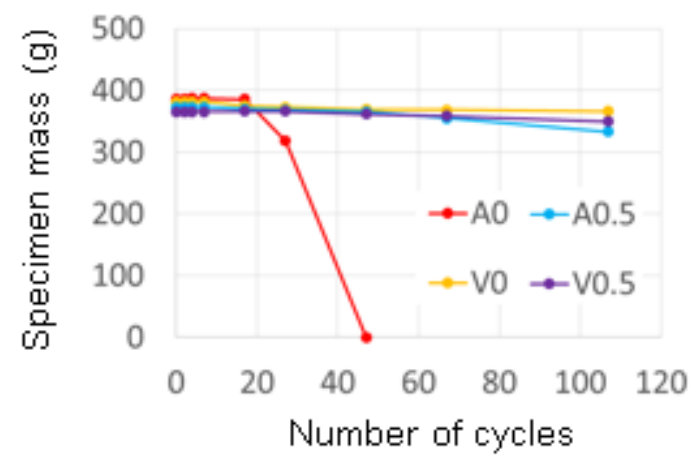

Figure 5. Mass change during freezing thawing test
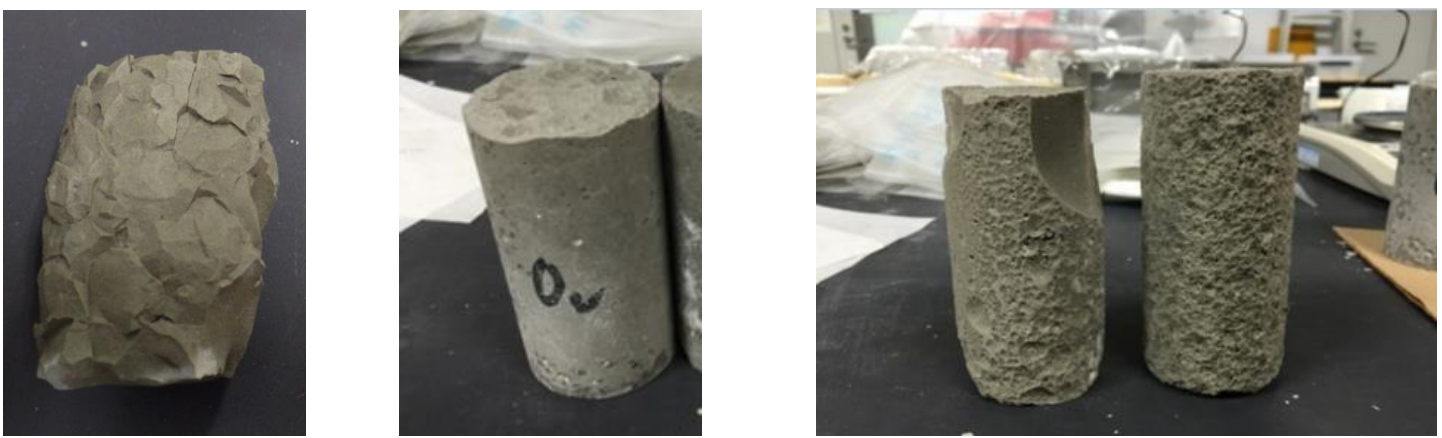

Photo 10. Specimens after freezing and thawing test (left to right: $\mathrm{A0}, \mathrm{V0}, \mathrm{A0.5}$, and V0.5)

\section{DISCUSSION}

\section{Microchannel geometry}

Water permeation into microchannels. The microchannels with both an inlet and an outlet filled immediately with water after the inlet was immersed. Conversely, the microchannels with only an inlet took a long time to fill (Photo 4). This delay is likely due to resistance from the air in the channels. These channels filled from their dead ends, a phenomenon explained by corner flow and film flow in which fluid travels to corners and surfaces of channels first [Harris et al. 1995]. The fluid reached the dead ends, where a meniscus then formed. Applying this concept to water permeation of concrete, it can be assumed that when a hardened concrete specimen is immersed in water, water permeates from all surfaces. This condition corresponds to that of microchannels without an outlet. When hardened cement paste specimens were immersed in water, it was observed that air was pushed from the specimens (Photo 10) as seen with the microchannels (Photo 5). In the study with microchannels, more air remained in the channels having larger ratios of cavity to neck volume. Air remained when a meniscus formed at the neck near the inlet before the cavity could fill with water (Photo 4). Such an air trapping mechanism suggests that the larger the cavity, or the smaller the neck of the ink bottle profile, the more air will become trapped in the channel. Even a straight channel retains large amounts of air, particularly as the permeation length increases [Han et al., 2006].

Effect of channel shape on frost damage. Freezing damaged only the microchannels with ink bottle profiles. One possible reason is that the freezing occurred near the channel walls, and water in the neck, which has a smaller cross sectional area than the cavity, froze completely before the water in the cavity. 
Ultimately, the freezing of the water remaining in the cavity is what caused the damage, as evidenced by the punching fractures centered within the cavities (Photo 8). More freezing and thawing cycles were required to damage smaller channels because the smaller channels (Photo 7) had less water volume, and therefore less expansion due to freezing, in addition to having thicker slide walls since less glass was removed during machining. Dense concrete with low W/C typically has high damage resistance under standard freezing and thawing testing [Hama et al. 2003], likely due to a similar mechanism as that of the small microchannels.

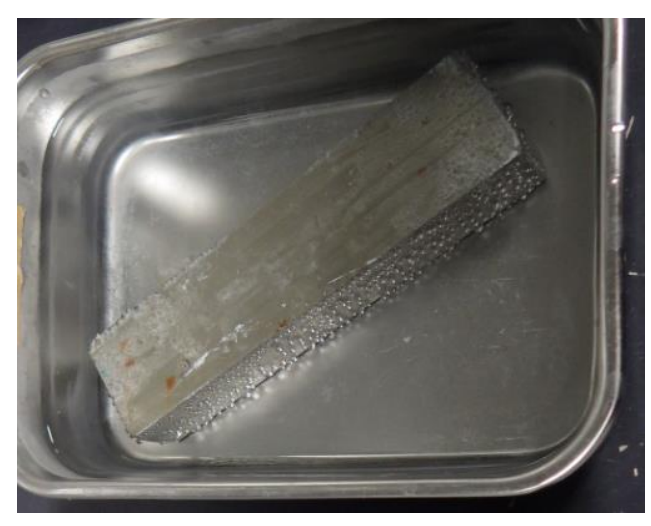

\section{Photo 11. Air pushed out from hardened cement paste}

Effect of remaining air on frost damage. Water increases its volume by $9 \%$ upon freezing. In the microchannels, the deformation of the air bubbles upon freezing indicated that the air absorbed some volume expansion of the frozen water (Photo 9). Photo 9 shows the initial area ratio of the air to be about $12 \%$ and that the area was reduced by only slightly after freezing. This shows that the volume expansion of freezing water was absorbed by the remaining air amongst other factors such as elastic deformation of the glass and pushing unfrozen water out of channels.

\section{Cement paste}

Bulk density, compressive strength, and porosity. Vacuum curing reduced both compressive strength and bulk density of the hardened cement paste specimen (figure 3), likely due to the air volume increase associated with vacuum curing. Figure 4 shows that V0 had lower porosity than A0. It is probable that V0 had more pores larger than $10 \mu \mathrm{m}$, which is outside of the measurement range of MIP. Vacuum curing increased porosity for pores with diameters of 100-200 $\mathrm{nm}$. Such changes in porosity indicate that the vacuum curing affects not only larger volumes of air such as entrapped and entrained air, but also smaller volumes of air on the nano scale. The fact that V0 and A0.5 had similar porosity curves for pores with diameters exceeding $20 \mathrm{~nm}$ demonstrates the similar effect of the AE water reducing agent and vacuum curing on pore structure.

Freezing and thawing test. Under atmospheric pressure, the specimen without $\mathrm{AE}$ water reducing agent (A0) collapsed at the 50th cycle. On the other hand, all other specimens remained intact through 100 cycles (figure 5) apart from surface deterioration of specimens A0.5 and V0.5 (Photo 10). The specimen cured under vacuum condition without $\mathrm{AE}$ water reducing agent (V0) avoided even surface damage. The above results indicate that vacuum curing is effective in improving resistance against frost damage, including surface deterioration, although it can reduce compressive strength and bulk density (figure 3). If vacuum curing enlarges the cavities of ink bottle geometries in cement paste specimens, and air remains entrapped, then the effect of the remaining air is improved resistance to frost damage as seen with the 
microchips. To confirm this, the relationship between remaining air volume in concrete and frost damage resistance needs to be investigated quantitatively.

\section{CONCLUSION}

The following general conclusions can be drawn from the study described in this paper:

- Model microchannels having an ink bottle geometry were damaged

- Larger ratios of cavity to neck volume in ink bottle microchannels result in more air entrapment within the cavity

- Model microchannels with air inside the cavity avoided frost damage

- Hardened cement paste specimens cured under reduced pressure had larger volumes of coarse pores (100-200 nm in diameter) compared with those cured under atmospheric pressure

- The hardened cement paste specimens cured under vacuum showed higher resistance to frost damage

\section{ACKNOWLEDGEMENTS}

Support for this research project was provided by LIXIL JS Foundation.

\section{REFERENCES}

Afrani, I., and Rogers, C. (1994). "The effects of different cementing materials and curing on concrete scaling." Cement, Concrete and Aggregates, 16(2), 132-139.

Bilodeau, A. and Malhotra, V. M. (1992). "Concretes incorporating high volumes of ASTM Class F fly ashes: Mechanical properties and resistance to deicing salt scaling and to chloride penetration." $A C I$ Special Publication, 132, 319-350.

Gebler, S. H. and Klieger, P. (1986). "Effect of fly ash on the durability of air-entrained concrete." ACI Special Publication, 91, 483-520.

Hama, Y., Senbu, O., and Tomosawa F. (2003). "Evaluation of frost resistance of concrete considering drying effect and capillary suction", Cement Science and Concrete Technology, 57, 266-272.

Han, A., Mondin, G., Hegelbach, N. G., de Rooij, N. F., Staufer, U. (1995). "Filling kinetics of liquids in nanochannels as narrow as $27 \mathrm{~nm}$ by capillary force, Journal of Colloid and Interface Science, 293(1), 151-157.

Harris, W., Radke, C. J., and Morris, s. (1995) "The motion of long bubbles in polygonal capillaries. Part 1. Thin films." Journal of Fluid Mechanics, 292, 71-94.

Kizito, J., Balasubramaniam, R., Nahra, H., Agui, J., and Truong, D. (2009). "Vapor-gas bubble evolution and growth in extremely viscous fluids under vacuum." 47th AIAA Aerospace Sciences Meeting including the New Horizons Forum and Aerospace Exposition, 215606.

Klieger, P. and Gebler, S.H. (1987). "Fly ash and concrete durability." ACI Special Publication, 100, 1043-1069.

Marchand, J., Pleau, R., and Gagne, R. (1995). "Deterioration of concrete due to freezing and thawing." Materials Science of Concrete, 4, 283-354.

Pigeon, M. and Pleau, R. (1995). "Durability of concrete in cold climates", E\&FN Spon, 94-127.

Pigeon, M., Pleau, R., and Aiitcin, P. C. (1986) Freeze-thaw durability of silica fume concrete: Scaling vs internal microcracking." Cement, Concrete and Aggregate, 8(2) 76-85. 
Sakata, N., Sugamata, T., Hayashi, D., and Hashimoto, M. (2012). "Investigation for relationship between frost damage resistance and air-void system in concrete." Concrete Research and Technology, 23(1), 35-47.

Tabata M., Koh Y., and Kamada E. (1986), "Experimental study on the factorial effects: Influence of environmental conditions on the frost damage of concrete (I)." Journal of structural and construction engineering, 367, 8-15. 